\title{
Role of trans rectal and scrotal ultra sonography in male infertility
}

\author{
Mohi J.K. ${ }^{1}$, Mittal M.S. ${ }^{2}$, Kaur N.K. ${ }^{3}$, Kaur A. ${ }^{4}$, Garg D. ${ }^{5}$ \\ ${ }^{1}$ Dr. Jaswinder Kaur Mohi, Associate Professor, ${ }^{2}$ Dr. Manoj Singh Mittal, Junior Resident, ${ }^{3}$ Dr. Navkiran Kaur, HOD, \\ ${ }^{4}$ Dr. Amarjit Kaur, Professor, Patiala, ${ }^{5}$ Dr. Deepak Garg Junior Resident, all authors are affiliated with Department of \\ Radio diagnosis, Patiala, Punjab, India.
}

Corresponding Author: Dr. Manoj Singh Mittal, Junior Resident, Department of Radio diagnosis, Patiala, Punjab, India. Email: mnjmittal.mittal@gmail.com

\begin{abstract}
Introduction: Investigation of male infertility is assuming greater importance with male factors implicated as the cause in up to half of the infertile couples. This prospective cross-sectional study aims to establish the role of transrectal and scrotal ultrasonography in male infertility. Besides routine investigations trans rectal and scrotal ultra sonography was performed to detect testicular and post-testicular etiology or abnormality. Aims: The aim of this cross-sectional study was to determine the role of transrectal and scrotal ultrasonography in the evaluation of male infertility and to compare the findings of ultrasonography with clinical and surgical findings. Material and Methods: The prospective crosssectional study was carried out on 50 patients visiting the ultrasound section of Rajindra Hospital; Patiala with complaint of infertility over the span of 2 years. All the patient undergoes transrectal and scrotal ultrasonography with high frequency transducer having a frequency of $7.5 \mathrm{MHz}$ and Color Doppler wherever indicated. Results: Ultra sonographic findings of scrotum in 50 patients reveals 24 cases of varicocele, 7 cases of epididymal cysts, 8 cases of hydrocele, 3 cases of epididymitis, 2 cases of cryptorchidism, 2 cases of testicular microlithiasis and 1 case of bilateral testicular cyst. Apart from the patient who had cryptorchidism, the testis of all the patients were normal in size, site, shape and echo pattern. The clinical palpation when compared to ultrasound was found to be have a sensitivity of 58.33\% and a specificity of $92.31 \%$. The positive predictive value was found to be $87.50 \%$ and negative predictive value $70.59 \%$. Conclusion: Trans rectal and scrotal ultrasound provides valuable information in the diagnostic evaluation of infertile men and substantially more pathological conditions can be detected on ultrasound compared to clinical palpation.
\end{abstract}

Key words: Transrectal, infertility, testicular.

\section{Introduction}

Infertility is a major life crisis for many couples. Investigation of male infertility is assuming greater importance with male factors implicated as the cause in up to half of the infertile couples. Infertility is defined as failure of conception after one year of unprotected inter course[1].

Male infertility is often correctable. It may be a presenting symptom of an occult underlying condition. The primary role of imaging is to identify an anatomically correctable cause of infertility. Imaging is critically important in the detection of testicular position and its abnormalities, as well as in the assessment of causes of obstructive azoospermia [2]. According to a multi-centric study conducted by WHO from 1982 to

Manuscript received: $18^{\text {th }}$ January 2018

Reviewed: $28^{\text {th }}$ January 2018

Author Corrected: $5^{\text {th }}$ February 2018

Accepted for Publication $9^{\text {th }}$ February 2018
$1985,20 \%$ of cases were attributed to male factors, $38 \%$ to female factors, $27 \%$ had causal factors identified in both partners, and $15 \%$ could not be satisfactorily attributed to either partner] In Indian couples seeking treatment, the male factor is the cause in approximately $23 \%$. A recent report on the status of infertility in India, states that nearly $50 \%$ of infertility is related to the reproductive anomalies or disorders in the male [3]. The causes of male infertility include pretesticular, testicular and post testicular causes. Testicular causes are mainly varicocele, cryptorchidism, exposure to gonadotoxins and post testicular causes include obstruction, disorders of ejaculation and erectile dysfunction [1]. Pretesticular: Acquired endocrino-pathies, Genetic endocrinopathies, Disorders of production or secretion of gonadotrophin-releasing hormone Disorders of luteinizing hormone, follicle stimulating hormone and androgen function. 


\section{Original Research Article}

Testicular : Varicocele, Genetics, Cryptorchidism, Exposure to gonadotoxins.

Post testicular: Obstruction, Immunologic, infertility Disorders of ejaculation, Erectile dysfunction.

The various causes of male infertility can be subcategorized as obstructive and non obstructive azoospermia or oligospermia. Nonobstructive disease includes varicocele, endocrinopathy, chromosomal abnormality, cryptorchidism, anabolic steroid abuse, gonadotoxin exposure, primary testicular failure, and ejaculatory disorders. Obstructive disorders include congenital bilateral absence of the vas deferens, ejaculatory duct obstruction, and prostatic cysts[4].

Transrectal ultrasound enables high resolution imaging of prostate, seminal vesicles and distal vas deferens and is implicated in diagnosing the cause of obstructive azoospermia Obstructive azoospermia manifest because of blockage of sperm transport or abnormalities of epididymis, vas deferens or ejaculatory duct. [1]

Scrotal ultrasound is used for evaluation of testicles, epididymis and proximal vas deferens and demonstrate abnormalities within the testis and para-testicular structures such as varicoceles and epididymal abnormalities as well as visualizing secondary changes caused by distal genital duct obstruction. [1]

\begin{abstract}
Aims
The aim of this cross-sectional study was to determine the role of transrectal and scrotal ultra sonography in the evaluation of male infertility and to compare the findings of ultra sonography with clinical and surgical findings.
\end{abstract}

\section{Material and Methods}

The prospective cross-sectional study was carried out on 50 patients visiting the ultrasound section of Rajindra Hospital, Patiala with complaint of infertility over the span of 2 years. All the patient undergoes transrectal and scrotal ultrasonography with high frequency transducer having a frequency of $7.5 \mathrm{MHz}$ and Color Doppler wherever indicated.

\section{Inclusion Criteria}

1. Males presenting with infertility and abnormal semen analysis.

2. Any case of infertility with coincident scrotal findings on clinical examination.

\section{Exclusion Criteria}

1. Any case of infertility attributable to known female causes.

2. Infertility due to impotence.

3. Infertility due to known pre-testicular causes.

Examination Technique- Transrectal ultrasound was performed with patient positioned in left lateral decubitus position. A high frequency endorectal transducer was used with a condom cover.

A generous amount of gel is put into the sphincter before inserting the probe. Patient asked to try and relax and "bear down" to open the sphincter as transducer is inserted slowly. Systemic evaluation of the terminal vas deferens, seminal vesicles, ejaculatory duct and prostate are carried out in axial and sagittal planes.

Scrotal ultrasound was performed with the patient supine. A towel was placed over the penis and the patient requested to draw the penis away from the scrotum and to present the scrotum in a suitable position for contact scanning. The testis and epididymis on each side was identified as completely as possible and compared for symmetry, size, texture and vascularity.

A composite assessment of the patient's history, findings on physical examination, laboratory investigations and results obtained from ultra sonography was compiled and analyzed statistically and a provisional diagnosis made.

\section{Results}

The mean age of infertile men was 28.92 years with a standard deviation of 4.58 years. Maximum numberof patients were between 26 and 30 years of age. Maximum number of cases had a sperm count between 5 and 10 M/ml i.e. 17 cases. Another 16 cases were suffering from Azoospermia.

The abnormality detected most often in infertile men on physical examination was varicocele, 16 cases out of 50.7 patients of hydrocele, 5 cases of epididymal cyst, 2 cases of cryptorchidism, 1 case of epididymis and 1 case having nonpalpable vas deferens were diagnosed. 
Original Research Article

Table-1: Findings on Local Examination.

\begin{tabular}{|c|c|c|c|}
\hline \multirow{4}{*}{ Findings } & No. of Cases & \%age \\
\hline \multirow{4}{*}{ Varicocele } & Left & 11 & $22 \%$ \\
\cline { 2 - 4 } & Right & 1 & $2 \%$ \\
\cline { 2 - 4 } & Bilateral & 4 & $8 \%$ \\
\hline \multirow{4}{*}{ Hydrocele } & Total & $\mathbf{1 6}$ & $\mathbf{3 2 \%}$ \\
\cline { 2 - 4 } & Left & 2 & $4 \%$ \\
\cline { 2 - 4 } & Right & 2 & $6 \%$ \\
\hline \multirow{4}{*}{ Others } & Bilateral & 3 & $\mathbf{1 4 \%}$ \\
\cline { 2 - 4 } & Total & $\mathbf{7}$ & $2 \%$ \\
\cline { 2 - 4 } & Epididymitis & 1 & $2 \%$ \\
\cline { 2 - 4 } & Non-Palpable Vas Deferens & 1 & $2 \%$ \\
\cline { 2 - 4 } & Single Left Testis & 1 & $10 \%$ \\
\cline { 2 - 4 } & Single Right Testis & 5 & $\mathbf{1 8 \%}$ \\
\hline
\end{tabular}

Ultrasonographic findings of scrotum reveals 24 cases of varicocele, 7 cases of epididymal cysts, 8 cases of hydrocele, 3 cases of epididymitis, 2 cases of cryptorchidism, 2 cases of testicular microlithiasis and 1 case of bilateral testicular cyst. Apart from the patient who had cryptorchidism, the testis of all the patients were normal in size, site, shape and echo pattern.

Table-2: Scrotal Ultrasound Findings.

\begin{tabular}{|c|c|c|c|}
\hline \multicolumn{2}{|c|}{ Findings } & No. of Cases & $\%$ age \\
\hline \multirow{4}{*}{ Varicocele } & Left & 14 & $28 \%$ \\
\hline & Right & 2 & $2 \%$ \\
\hline & Bilateral & 8 & $16 \%$ \\
\hline & Total & 24 & $48 \%$ \\
\hline \multirow{4}{*}{ Hydrocele } & Left & 1 & $2 \%$ \\
\hline & Right & 1 & $2 \%$ \\
\hline & Bilateral & 6 & $12 \%$ \\
\hline & Total & 8 & $16 \%$ \\
\hline \multirow{4}{*}{ Epididymal Cyst } & Left & 1 & $2 \%$ \\
\hline & Right & 0 & $0 \%$ \\
\hline & Bilateral & 6 & $12 \%$ \\
\hline & Total & 7 & $14 \%$ \\
\hline \multirow{4}{*}{ Epididymitis } & Left & 1 & $2 \%$ \\
\hline & Right & 1 & $2 \%$ \\
\hline & Bilateral & 1 & $2 \%$ \\
\hline & Total & 3 & $6 \%$ \\
\hline \multirow{5}{*}{ Others } & Bilateral Testicular Cyst & 1 & $2 \%$ \\
\hline & Left Undescended & 1 & $2 \%$ \\
\hline & Right Undescended & 1 & $2 \%$ \\
\hline & Testicular Microlithiasis & 2 & $4 \%$ \\
\hline & Total & 5 & $10 \%$ \\
\hline
\end{tabular}

The abnormality found in highest number of patients on clinical palpation and ultrasound was varicocele. Varicocele was detected in 16 patients on clinical examination and 24 patients were found on ultrasound. Hydrocele was detected in 8 patients in comparison to 7 cases detected on clinical examination. Ultrasound detect 7 cases of epididymal cysts and 5 cases were diagnosed on clinical examination. Some ultrasound detects 3 cases of epididymitis and only 1 case of epididymitis was diagnosed on clinical examination. The total number of abnormalities detected by ultra sound were significantly greater as compared to physical examination (p-value 0.001, statistically significant). 


\section{Original Research Article}

Table-3: Comparison of clinical and ultrasound significant findings in infertile males

\begin{tabular}{|c|c|c|c|c|}
\hline \multirow{2}{*}{ Findings } & \multicolumn{2}{|c|}{ Clinical Findings } & \multicolumn{2}{c|}{ Ultrasound Findings } \\
\cline { 2 - 5 } & No. of Cases & \%age & No. of Cases & $48 \%$ \\
\hline Varicocele & 16 & $32 \%$ & 24 & $16 \%$ \\
\hline Hydrocele & 7 & $14 \%$ & 8 & $14 \%$ \\
\hline Epididymal Cyst & 5 & $10 \%$ & 7 & $84 \%$ \\
\hline Epididymitis & 1 & $58 \%$ & 42 & \\
\hline Total & 29 & \multicolumn{2}{|c}{25.81} \\
\hline$\chi 2$ & \multicolumn{2}{|c|}{0.001} \\
\hline
\end{tabular}

Transrectal ultrasound detect 2 cases of absent vas deferens, 1 case of midline prostatic cyst and 1 case of seminal ductal ectasia. Mid line prostatic cyst was confirmed on surgery.

Table-4: Sensitivity, specificity, positive predictive, and negative predictive values of clinical findings as compared to ultrasound (varicocele).

\begin{tabular}{|c|c|c|c|}
\hline True Positive & False Positive & True Negative & False Negative \\
\hline 14 & 2 & 24 & 10 \\
\hline
\end{tabular}

\section{Statistical Analysis}

\begin{tabular}{|c|c|c|c|}
\hline Sensitivity & Specificity & Positive Predictive Value & Negative Predictive Value \\
\hline $58.33 \%$ & $92.31 \%$ & $87.50 \%$ & $70.59 \%$ \\
\hline
\end{tabular}

The clinical palpation when compared to ultrasound was found to be have a sensitivity of $58.33 \%$ and a specificity of $92.31 \%$. The positive predictive value was found to be $87.50 \%$ and negative predictive value $70.59 \%$.

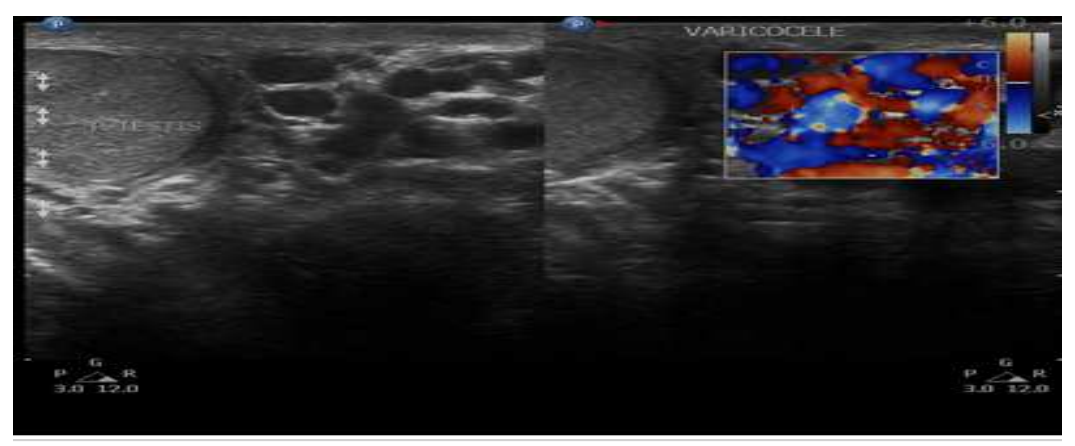

Figure 1: Multiple dilated tortuous anechoic tubular channels are seen posterior to both testis. Flow seen in dilated vessels which increases on Valsalva indicating bilateral varicocele.

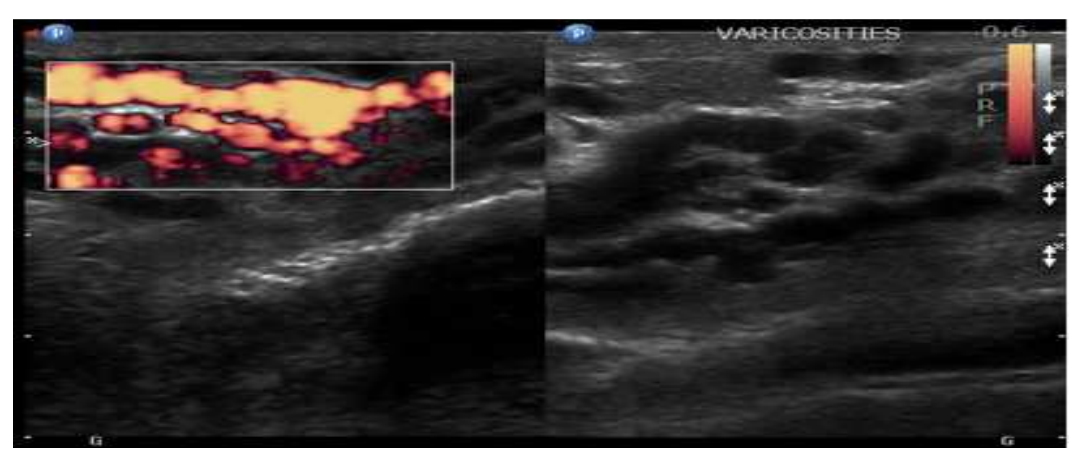

Figure 2: Multiple dilated tortuous anechoic tubular channels are seen posterior to both testis. Flow seen in dilated vessels which increases on Valsalva indicating bilateral varicocele. 


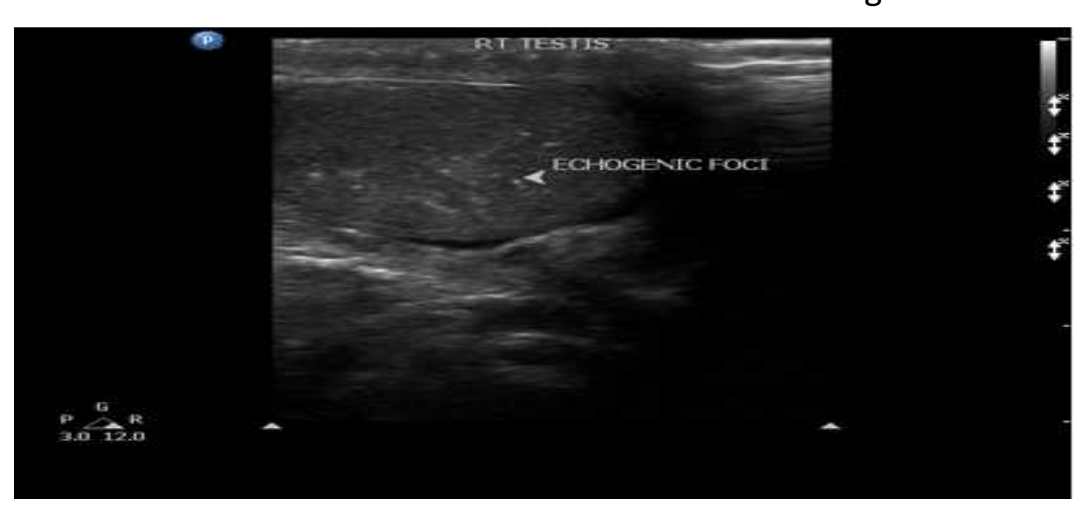

Figure 3: Multiple small non-shadowing hyper echoic foci are seen with in right testicular parenchyma indicating right testicular microlithiasis.

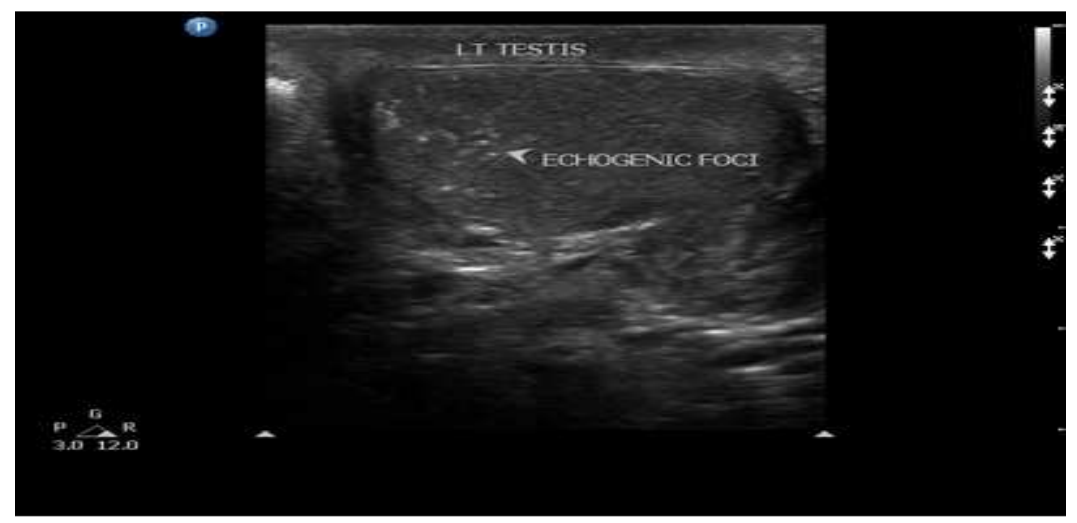

Figure 4 : Multiple small non-shadowing hyper echoic foci are seen within left testicular parenchyma indicating left testicular microlithiasis.

\section{Discussion}

Over the past decade, the rapid development of novel management approaches for male factor infertility has enabled many of these men, previously believed to be infertile, the ability to become fathers. Male infertility contributes to $50 \%$ of cases overall.

Scrotal and transrectal ultrasound is an important investigation for early diagnosis and management of infertile male subjects. In some cases, fertility can be restored to patient with correction of etiology which is occluding the part of ductal system. The present study was conducted on 50 infertile men in the Department of Radiodiagnosis, GMC and associated Rajindra hospital, Patiala with objective to establish the role of transrectal and scrotal ultrasonography in male infertility. Radiological findings were correlated with clinical and surgical findings.

In the present study, the mean age of patients was $28.92+4.58$ years with the range of 21-40 years which was comparable to the study conducted by Brunereau et al [5] (2000) where the mean age of the patients was 29.20 years with a range of 24-40 years. Pethiyagoda et al [6] (2017) reported mean age of 35.15 years with age range of 25-40 years. This represents changing socioeconomic trends of the society particularly in the developed countries which has led to delayed marriage and procreation. The present study included the patients who had a sperm count of less than $20 \mathrm{M} / \mathrm{ml}$, in keeping with the WHO guidelines. The present study group included 16 patients with azoospermia and another 17 patients with a sperm count between 5 and $10 \mathrm{M} / \mathrm{ml}$. Goullet et al [7] (2000) conducted a consecutive study on 609 infertile men of whom 191 had azoospermia and 418 had oligoastheno-teratospermia. Moon et al [8] (2006) conducted his study on 20 infertile men with azoospermia. Qublan et al [9] (2007) conducted his study on 234 infertile men with a sperm count of less than $10 \mathrm{M} / \mathrm{ml}$. Semen parameters in present study are comparable to parameters in study conducted by Brunerueau et al [5] (2000).

In the present study, the commonest abnormality detected on palpation, was varicocele. Varicocele was detected in $16(32 \%)$ cases on physical examination. Eskew et al [10] (1993) in study on 262 infertile men found that $89(34 \%)$ patients had clinically palpable varicocele and $168(64 \%)$ on ultrasound examination. 


\section{Original Research Article}

Preutthipan and Nicholas [11] (1995) found that out of 110 patients, 32 had left sided varicocele, 2 had right sided and 6 patients had bilateral varicocele on clinical palpation. The incidence of various pathological findings as detected on scrotal ultrasound in the present study was varicoceles (48\%), hydrocele (16\%), epididymal cysts (14\%), epididymitis (6\%), cryptorchidism (4\%), testicular microlithiasis (4\%) and bilateral testicular cyst in $2 \%$ of cases. Barring three patients, two with cryptorchidism and one with hydrocele, all the patients were found to be having testes which were normal in size, shape and echo pattern and showed no focal lesion.

Gordon et al [12] (2008) in their study on 53 infertile men found varicoceles in 18 (34\%), bilateral small testes in four $(8 \%)$, unilateral small testis in four $(8 \%)$, epididymal cysts in four (8\%), testicular microlithiasis in two $(4 \%)$, testicular tumor in one $(2 \%)$, thickened epididymis in one. Jequier et al [13] (2014) in their study on 1203 infertile men found varicocele in 52\% cases, epididymal cyst in $22 \%$ cases, testicular microlithiasis in $6 \%$ cases, hydrocele in $4 \%$ and testicular cancer in $0.4 \%$ cases. Ibrahim et al [14] (2017) in their study on 115 infertile men found varicocele in $39 \%$ cases, hydrocele in $26 \%$ cases, epididymo-orchitis in $7 \%$ cases, epididymal cyst in $5 \%$ cases and testicular microlithiasis in $4 \%$ cases.

In the present study the clinical palpation revealed that 11 patients had left varicocele, 4 had bilateral varicoceles and 1 had right varicocele. On ultrasound it was found that 14 patients had left varicocele, 8 had bilateral varicoceles and 2 had right varicocele.

Dogra et al [15] (2003) in their study of 1372 infertile men diagnosed varicocele in $29 \%$ of patients on ultrasound examination. Out of total patients diagnosed as varicocele on ultrasound, only $60 \%$ had a clinically palpable varicocele. They found that sensitivity and specificity of varicocele detection approaches 100\% with color doppler ultra sound. Sakamoto et al [18] (2006) in their study on 545 infertile men found varicocele in $45 \%$ cases on physical examination as compared to $51.4 \%$ cases detected on ultrasound.

Transrectal ultrasound detect 2 cases of absent vas deferens (4\%), 1 case of midline prostatic cyst $(2 \%)$ and 2 cases of dilated seminal vesicles (4\%). Ho et al [16] (2015) in their study on 387 patients found congenital absence of vas deferens in $8 \%$ of patients. Findings in the present study are almost similar to findings in study done by Abdul wahed et al [17] (2013).
The clinical palpation when compared to ultrasound was found to be have a sensitivity of $58.33 \%$ and a specificity of $92.31 \%$. The positive predictive value was found to be $87.50 \%$ and negative predictive value $70.59 \%$. Preutthipan and Nicholas [11] (1995) showed that clinical examination had sensitivity of $73.90 \%$ specificity of $90.60 \%$, positive predictive value of $85 \%$ and negative predictive value of $82.80 \%$ for diagnosis of varicocele as compared to ultrasound. Sakamoto et al [18] (2006) in their study on 545 infertile men found that clinical examination had a sensitivity of $58.4 \% \%$, specificity of $79.3 \%$, positive predictive value of $79.3 \%$ and negative predictive value of $67.3 \%$ for diagnosis of varicocele as compared to ultrasound.

\section{Conclusion}

A systemic, logical and thorough evaluation of infertile men is mandatory to identify patients with potentially correctable defects. Scrotal ultrasound can detect abnormalities in mediastinum testis, epididymis and proximal vas deferens. It can also show secondary changes due to obstructive abnormalities in distal genital duct system. Transrectal ultrasound enables high resolution imaging of prostate, seminal vesicles and distal vas deferens and is implicated in diagnosing the cause of obstructive azoospermia. Imaging has an important complementary role to clinical examination and laboratory analyses, in demonstrating the precise anatomy and level of abnormality. The diagnosis of testicular and post-testicular causes indicates whether the abnormality can be corrected surgically. An accurate diagnosis is a prerequisite for ensuring appropriate and effective treatment. A scrotal ultrasound finding suggesting OA is usually followed by TRUS with differentiation of proximal from distal obstruction.

The present study suggested that transrectal and scrotal ultrasound provides valuable information in the diagnostic evaluation of infertile men and substantially more pathological conditions can be detected on ultrasound compared to clinical palpation.

\section{Limitations}

1. Surgical findings of all diagnosed cases could not be included in present study which would have provided us with more critical information regarding sensitivity and specificity of ultrasound.

2. Small sample size

3. Technical /operative limitations.

Funding: Nil, Conflict of interest: None. Permission of IRB: Yes 


\section{References}

1. Ammar T, Sidhu PS, Wilkins CJ. Male infertility: the role of imaging in diagnosis and management. $\mathrm{Br} \mathrm{J}$ Radiol. 2012 Nov;85 Spec No 1:S59-68. doi: 10. 1259/ bjr/31818161. Epub 2012 Jul 4.

2. Raza SA, Jhaveri KS. Imaging in male infertility. Radiol Clin North Am. 2012 Nov;50(6):1183-200. doi: 10. 1016/j.rcl.2012.08.006.

3. Kumar N, Singh AK. Trends of male factor infertility, an important cause of infertility: A review of literature. J Hum Reprod Sci. 2015 Oct-Dec; 8(4):1916. doi: 10.4103/0974-1208.170370.

4. Simpson WL Jr, Rausch DR. Imaging of male infertility: pictorial review. AJR Am J Roentgenol. 2009 Jun;192(6 Suppl):S98-107 (Quiz S108-11). doi: 10. 2214/AJR.07.7109.

5. Brunereau L, Fauchier F, Fernandez P, Blais G, Royere G, Pourcelot L, Rouleau P, Tranquart F. [Sono graphic evaluation of human male in fertility]. J Radiol. 2000 Dec;81(12):1693-701.

6. Pethiyagoda AUB and Pethiyagoda K. Scrotal ultrasonography in the assessment of sub fertile males. International Journal of Scientific and Research Publications 2017;7(5):873-76.

7. Goullet E, Rigot JM, Blois N, Lemaitre L, Mazeman E. [Role of systematic crotal ultra sonography in the management of male infertility: prospective study of 609 cases]. Prog Urol. 2000 Feb;10(1):78-82.

8. Moon MH, Kim SH, Cho JY, Seo JT, Chun YK.ScrotalUS for evaluation of infertilemen with azoospermia. Radiology. 2006 Apr; 239(1):168-73. Epub 2006 Feb 7.

9. Qublan HS, Al-Okoor K, Al-Ghoweri AS, AbuQamar A. Sonographic spectrum of scrotal abnormallities in infertile men. J Clin Ultrasound. 2007 Oct;35 (8):437-41.
10. Eskew LA, Watson NE, Wolfman N, Bechtold R, Scharling E, Jarow JP. Ultra sonographic diagnosis of varicoceles. Fertil Steril. 1993 Oct;60 (4): 693-7.

11. Preutthipan S, Nicholas OA. Comparative study between scrotal physical examination and scrotal ultra sonography in the detection of varicocele in men with infertility. J Med Assoc Thai. 1995 Mar;78 (3):135-9.

12. Gordon SJ, Otite U, Mahesh kumar P, Cannon P, Nargund VH. The use of scrotal ultrasonography in male infertility. BJU Int. 2001 Mar;87(4):417-8.

13. Jequier AM, Phillips N, Yovich JL. The Diagnostic Value of a Routine Genito-Urinary Ultrasound Examination for Men Attending an Infertility Clinic. Andrology \& Gynecology: Current Research. 2014; $2: 4$.

14. Ibrahim M, Tabari A, Igashi J, Lawal S, Ahmed M. Scrotal doppler ultrasound evaluation in Zaria, Nigeria. Nigerian Journal of Basic and Clinical Sciences. 2016; $13(2): 89$.

15. Dogra VS, Gottlieb RH, Oka M, Rubens DJ. Sonography of the scrotum. Radiology. 2003 Apr; 227(1):18-36. Epub 2003 Feb 28.

16. Ho KL, Tsu JH, Tam PC, Yiu MK. Disease spectrum and treatment patterns in alocalmale infertility clinic. Hong Kong Med J. 2015 Feb; 21(1): 59.doi:10.12809/hkmj144376. Epub 2015 Jan 2.

17. Abdulwahed S, Mohamed E, Taha E, Saleh M, Abdelsalam Y, El Ganainy E. Sensitivity and Specificity of Ultra sonography in Predicting Etiology of Azoospermia. Urology. 2013;81(5):967-71.

18. Sakamoto H, Saito K, Shichizyo T, Ishikawa K, Igarashi A, Yoshida H. Color Doppler ultra sonography as a routine clinical examination in male infertility. Int $\mathbf{J}$ Urol. 2006 Aug;13(8):1073-8.

\section{How to cite this article?}

Mohi J.K, Mittal M.S, Kaur N.K, Kaur A, Garg D. Role of trans rectal and scrotal ultra sonography in male infertility. Int J Med Res Rev 2018;6 (02):78-84. doi:10.17511/ijmrr. 2018.i02.03. 